American Journal of

Health, Medicine and Nursing Practice (AJHMN)

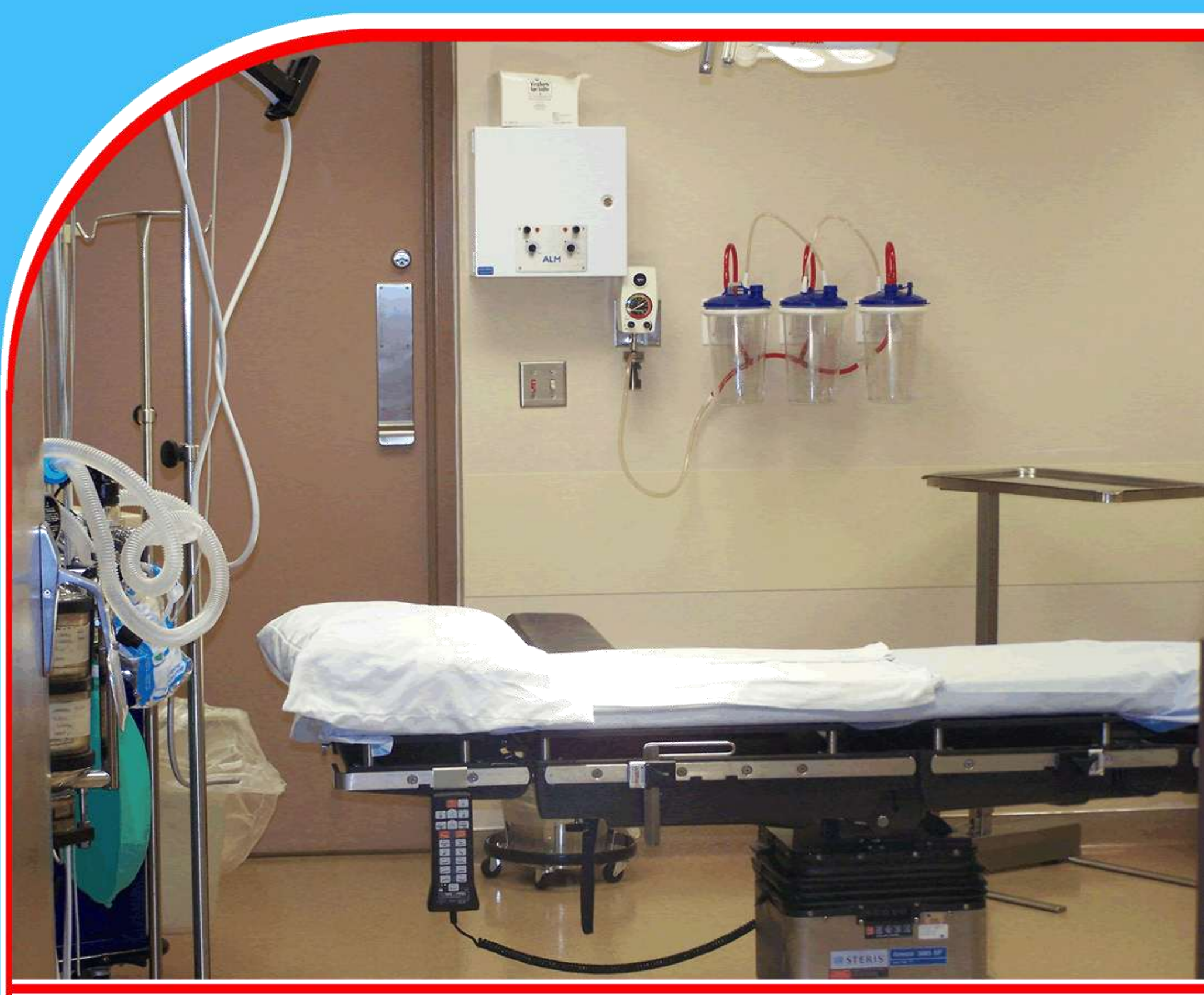

ASSESSMENT OF PATIENT SATISFACTION WITH AN EFOLDER AND NON- E-FOLDER SYSTEMS IN TWO DISTRICT HOSPITALS IN THE EASTERN REGION OF GHANA

Dorothy Tawiah

Dr. Genevieve Aryeetey

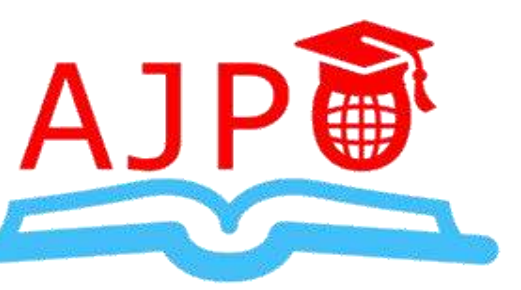




\title{
ASSESSMENT OF PATIENT SATISFACTION WITH AN E-FOLDER AND NON- E- FOLDER SYSTEMS IN TWO DISTRICT HOSPITALS IN THE EASTERN REGION OF GHANA
}

\author{
Dorothy Tawiah \\ Post Graduate Student \\ School of Public Health, College of Health Science, University of Ghana \\ Corresponding author's Email: dottawiah@gmail.com \\ Dr. Genevieve Aryeetey \\ Lecturer, School of Public Health, College of Health Science, University of Ghana \\ University of Ghana
}

\begin{abstract}
Background: A patient satisfied with care will translate into increased facility utilization and reflect organizational efficiency. Among several listed indicators, waiting time on a visit and staff interaction with him/her is a lasting impression that affects the out-patients' satisfaction. The E-folder is proposed as one of the measures of improving patient satisfaction at the outpatient clinic.

Objectives: This study assessed patient satisfaction at the outpatient department in an E- folder and non E-folder systems; specifically, average time spent by patients to assess full care, determine factors influencing patient waiting time, assess impact of electronic folder use on patient provider-relationship and patient's satisfaction with care.

Methods: The study used a cross-sectional design and was conducted in Kade and New Tafo government hospitals, in the Eastern Region of Ghana. Observational time and motion study with exit interview were employed to collect quantitative data, using an observational record sheet and a semi structured questionnaire as tools respectively. A sample size of 422 was used with consecutive sampling of outpatients as target group. Patients selected were followed as they moved though the various sections of the OPD and stationed research assistants in each section recorded time in and out. The pharmacy was used as final section but patients who did not use the pharmacy were exited in the last section visited. Interviews were conducted at this point. Data was entered in Microsoft Office Excel 2013 version and imported into STATA SE version 15 for analysis. T-test, Pearson's Chi- square and binary logistic regression model were used to analyst data. All significance level was set at a 0.05 alpha level and $95 \%$ confidence interval of estimates provided. Findings were compared between facilities.

Results: Average total waiting time was $236.15 \pm 81.28$ for E-Folder facility and $365.83 \pm 122.25$ non-Efolder facility. The main cause of prolong waiting time was 'Queue not followed accordingly (75.6\%) and Many patients in queue (84/6\%) in No- E-folder facility with percentages of $25.8 \%$ and $35.8 \%$ in E-folder facility. Both facilities rated patient provider relationship 'Good' with over $80 \%$. Overall satisfaction with care was $76.5 \%$ (E- Folder) and 50.5\% (Non -E-Folder).

Conclusion: Total waiting time exceeds recommended 90-120 minutes. Time is the most significant indicator of patient satisfaction. The Type of record system has significant influence on patient satisfaction.
\end{abstract}

Recommendation: The E-folder system coupled with a multi-unit and managerial effort, are recommended as means of improving patient satisfaction.

Key words: Satisfaction, Outpatient, Waiting time, Provider, Perception 


\subsection{INTRODUCTION}

Satisfaction is currently an important marker in the healthcare space. It has swiftly taken precedence over the traditional method of assessing quality care which Babu and Sreenisvas (2012) described as curative care success; as rated by the healthcare provider. Patient satisfaction is a reflection by patient to ascertain if their expectation of care at a health facility has been fulfilled (Mohd \& Chakravarty, 2014). Report of the patient's judgement has become a primary form of healthcare quality measurement, as evidence has shown that information from patients can facilitate quality improvements. Various studies (Patel \& Patel, 2017; Pandit, Varma \& Amruta, 2016; Batbaatar, Dorjdagva \& Luvsannyam, 2016) have listed several indicators of outpatient satisfaction and paramount among them are waiting time and patient-provider relationship. Currently, most patients are more aware and well informed; therefore, expects a high standard of care delivery.

The outpatient department is described as the gem of any health facility. It often represents an overview of what the facility offers and an initial connection point. For most facilities, it attends to all categories of patients, with the end of the system being taking medication home (ambulatory service), being detained or being admitted to a ward. Kumar, Adhikari, Ray Indu, Bhattacharya and Das (2018) write that the bulk of out-patient service is characterized by patients who take medication home after consultation. For the ambulant patient, the main concern is how much time they have to spend at the hospital in the day and their impression of behavior that staff show to them during this time; in addition to receiving the necessary service needed, cost effectively in a clean environment (Olomi, Mboya \& Manongi, 2016).

Although health care is usually delivered within a reasonable period, most people intuitively respond to long waiting times in an undesirable way. In view of this many countries universally, are pushing initiatives to improve waiting time at the OPD. One solution adopted is the incorporation of Information Technology; precisely, electronic health record system. This computerization however, has been found to alter the balance inherent in the patient-provider relationship which is also an important pointer of the patient's satisfaction.

Pearce, Arnold, Philips, Trumble and Dwan (2011) elaborated that it affects consultation, patient centeredness and increases the cognitive load on the healthcare provider. These affect the quality of patient-provider interaction during consultation. The practice is now evolving Ghana's health system which has been characterized by operations using the manual record system; where patients upon entry into a facility, pick up a folder and follow the necessary procedures to access care at the outpatient department. Ghana, even though had parts of health records stored by ICT in the past decade; the country officially launched the electronic folder use in 2017. With this official introduction of the system where after registration the patient access care without the use of a folder; it is currently under pilot in regional and district facilities pending policy documentation. In the Eastern region, some facilities have adopted the electronic folder system and others have not. With the current reports of effect linked with electronic health record use especially, on two important markers of satisfaction at the OPD (waiting time and patient provider- relationship) this study sets out to bring to bear the situation in Ghana compared to the traditional manual record system. 


\subsection{Statement of the Problem}

The healthcare domain is continuously evolving globally and delivering medical care that meets patients' expectations now involves more than just helping the patient to get well. Unlike the inpatient whose satisfaction according to Shoenfelder, Klewer and Kluger (2011). is based on reflection of services received over the period of hospitalisation and ultimately, recovery from ailment; the outpatient's satisfaction with care is an immediate impression of care. Being the initial point of call for clients to any health facility, the outpatient clinic is also an interconnected mass of units and moving through these various sessions to assess full care can be distressful to patients. Majority reports on patient satisfaction have identified prolong waiting time and poor patient-staff relationship as key indicators of patient satisfaction with care at the OPD (Ahmad, Khairatul, \& Farnaza, 2017; Atinga, Abekah- Nkrumah, \& Domfeh, 2011).

Some studies (Mathai, Shiratudin \& Sohel, 2017; Weeks, 2013; Achampong, 2012; Pearce, et al., 2011) have reported that the type of record system used at the outpatient clinic is an essential factor influencing these high rated indicators of patient satisfaction; among other factors such as patient characteristics, health insurance use resulting in high influx of patients and resource constraints especially in developing countries (Duku, Amponsah, Janssens \& Pradha, 2018). Under the manual record system, Ofosu - Kwarteng (2012) in his study at the Eastern region of Ghana recounted that $48 \%$ of patients were found to spend 5-6 hours to assess full service at the OPD. $46 \%$ spent $3-4$ hours and $6 \%$ spent $1-2$ hours. This indicates that only $6 \%$ fall within the standard waiting time (90-120 minutes) proposed by the WHO and evident in the usually overcrowded OPD's with long queues in most sessions.

According to Evans' (2016) report, in the western world automating a patient's records have been found as one of the effective means of curbing the problems associated with the manual record system; that add to patient waiting time while improving other quality indicators (Job, Bachman, Schmid, Thiel \& Ivic, 2016). The challenge that has arisen with this system despite its hailed benefits is the computer as a 'third person' in the communication process between the provider and patient which is an important factor noted to be diminishing the relationship between these two (Ehrenfield \& Wanderer, 2018).

Patient dissatisfaction leads to health facility shopping and therefore influences utilization, reduces patient trust in the health system, causes late reporting of ailment and resorting to detrimental alternative care leading to severe complications (Kulkarni (2018). These affect the overall goal of attaining universal healthcare. With these reports, fostering patient- provider relationship, reducing wait times and incorporating technology have been suggested as critical to meet outpatient satisfaction (Patel \& Patel, 2017; Xie \& Or, 2017). At an official launch for Electronic Health Record (Commonly called Electronic folder system) in Ghana in 2017, the chief of staff mentioned that it will help reduce waiting time and better other quality care indicators. If indeed it is serving its purpose then over a year of implementation, study findings should reflect significant improvements in patient satisfaction compared to the manual record system. 
American Journal of Health, Medicine and Nursing Practice

ISSN 2520-4017 (Online)

Vol.5, Issue 3, pp $53-69,2020$

Www.ajpojournals.org

\subsection{Objectives of the Study}

1. To assess the average time spent by patients to access full care under both systems.

2. To determine factors influencing patient waiting time under both record systems

3. To assess influence of type of record system use on patient provider-relationship.

4. To determine the proportion of patients satisfied with care under both record systems.

5. To determine the influence of waiting time and type of record system on patient satisfaction.

\subsection{LITERATURE REVIEW}

Satisfaction with care is a relative judgment of the patient, who measures it, based on his/her health needs prior to assessing health care, expectations of the health system, and experience of healthcare. It is an evaluation that reflects the perceived differences between expectations of the patient to what is actually received during the process of care (Xie \& Or, 2017). This phenomenon has become a priority for healthcare managers as it is an important indicator of total quality management. This evolution of patient centered care according to Nyunt (2016), has come to light due to increased lay knowledge through awareness creation, patient skepticism about medicine, manager accountability, and competitiveness as a result of increasing numbers in health facilities, National Health Insurance and accreditation requirements as well as the shift from objective to subjective medicine. Various theories supporting patient satisfaction have been put out including the healthcare quality theory which dwells on the technical competence of provider alongside the organization, as well as interpersonal processes of patient care; and the expectancy value theory that stresses on patient's beliefs, values and prior expectation regarding care (Mukhtar, Anjum, Shahzad, Hamid, Masood \& Mustafa, (2013).

As cited by Bouayad, Ialynytchev and Padmanabhan (2017), the concept of recording patients information and storing it developed in the early 1970s aimed at ensuring continuity of care, error reduction, patient input on treatment options, and building patient-provider encounters. It serves as basis for all care rendered to a patient. The patient health record is a collection of documents that give account of each clinical event occurrence during the period a patient seek treatment. According to Garba (2018), its content includes patient's demographic and identification data, clinical notes by designated service providers who attend to patients including doctors, nurses, physiotherapists and anaesthetists, recording of discussion with patient and/or accompanying person, reference notes to another professional for co-consultation, Diagnostic investigations, management plan, at-own-risk refusal of treatment and consent forms, printouts from monitoring equipment (example, Electro-cardiogram), letters to and from other health professionals and records of instructions relevant to the care of the patient.

Ahmad, Khairatul and Farnaza (2017) express waiting time as the period from entry to the time of exit of a patient from a health facility after assessing full service needed. It therefore includes actual service times and waiting periods in between service times as patient moves through the various flow points. Theorist of healthcare processes and services have described the OPD as characterized by queues in which a patient join on arrival, wait for and obtain service needed and leave. In line with this, the queuing theory has been used widely to describe this structure. This 
theory, originates from the field of mathematics based on S.D. Poisson's idea (1781-1840). It defines a set of analytical techniques describing situations of congestion and blockage (Koka, Badshah \& Shah, 2017). Adan and Reding (2015) elaborate on a division of this model into input and output; the commonest being the single-server single queue model. Here, a single queue of patients is served by a provider at a time.

Researchers (Greenfield et al., 2014) ıdentified timely delivery of care and patient experiences whiles receiving care as paramount quality indicators at the OPD. Mehra et al., (2016) concurred saying, these two matters most to the patient and underlies their perception of quality care; hence, satisfaction or dissatisfaction. Duku et al., (2018) found that patients spend an average of 300-360 minutes to assess full care at the OPD. Various studies have indicated that patients who waited more than two hours at the OPD expressed dissatisfaction with care (Duku et al., 2018; Belayneh et al., 2017; Musingizi, 2013; Weeks, 2013; Kwarteng, 2012); most often this time elapses before a doctor is seen. Musingizi, (2013) reported that only 5\% of total waiting time was spent on providing service, influencing satisfaction rates negatively. Enquirers (Datuk, Roslan, Noor, Abu, Azman, Umapathy \& Wan, 2011) concluded that in a district hospital, contact time with the medical provider was 15 minutes with average total waiting time of 85 minutes before consultation. This resulted in almost $80 \%$ of respondents expressing acceptability.

\subsection{RESEARCH METHODOLOGY}

The study used a cross-sectional design and was conducted in Kade and New Tafo government hospitals, in the Eastern Region of Ghana. Observational time and motion study with exit interview were employed to collect quantitative data, using an observational record sheet and a semi structured questionnaire as tools respectively. A sample size of 422 was used with consecutive sampling of outpatients as target group. Patients selected were followed as they moved though the various sections of the OPD and stationed research assistants in each section recorded time in and out. The pharmacy was used as final section but patients who did not use the pharmacy were exited in the last section visited. Interviews were conducted at this point. Data was entered in Microsoft Office Excel 2013 version and imported into STATA SE version 15 for analysis. T-test, Pearson's Chi- square and binary logistic regression model were used to analyse data. All significance level was set at a 0.05 alpha level and $95 \%$ confidence interval of estimates provided. Findings were compared between facilities

\subsection{DISCUSSION OF FINDINGS.}

\subsection{Demographic characteristics of study participants.}

Table1 and figure 1 below shows the description of demographic characteristics of the study participants. A total of 442 study participants were involved in the study with equal number of participants interviewed from both facilities. An average age of 54.9 years was estimated among participants from E-folder facility and 53.1 years from the non-E-folder facility. Most (28.2\%) of the participants were within the age range 50-59 years (E-folder (25.3\%) and non-E-folder $(31.2 \%)$ ). Majority $(72.9 \%)$ of them were females with $75.6 \%$ dominating participants in the Efolder facility whiles $70.1 \%$ of females constituted those from the non-E-folder facility. In both cases, majority of the study participants were old clients. Only $10.86 \%$ and $9.95 \%$ respectively from E-folder and Non-folder Facilities had Tertiary education. 
American Journal of Health, Medicine and Nursing Practice

ISSN 2520-4017 (Online)

Vol.5, Issue 3, pp $53-69,2020$

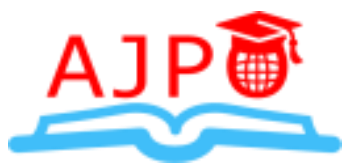

www.ajpojournals.org

Table 1: Demographic characteristics of study participants

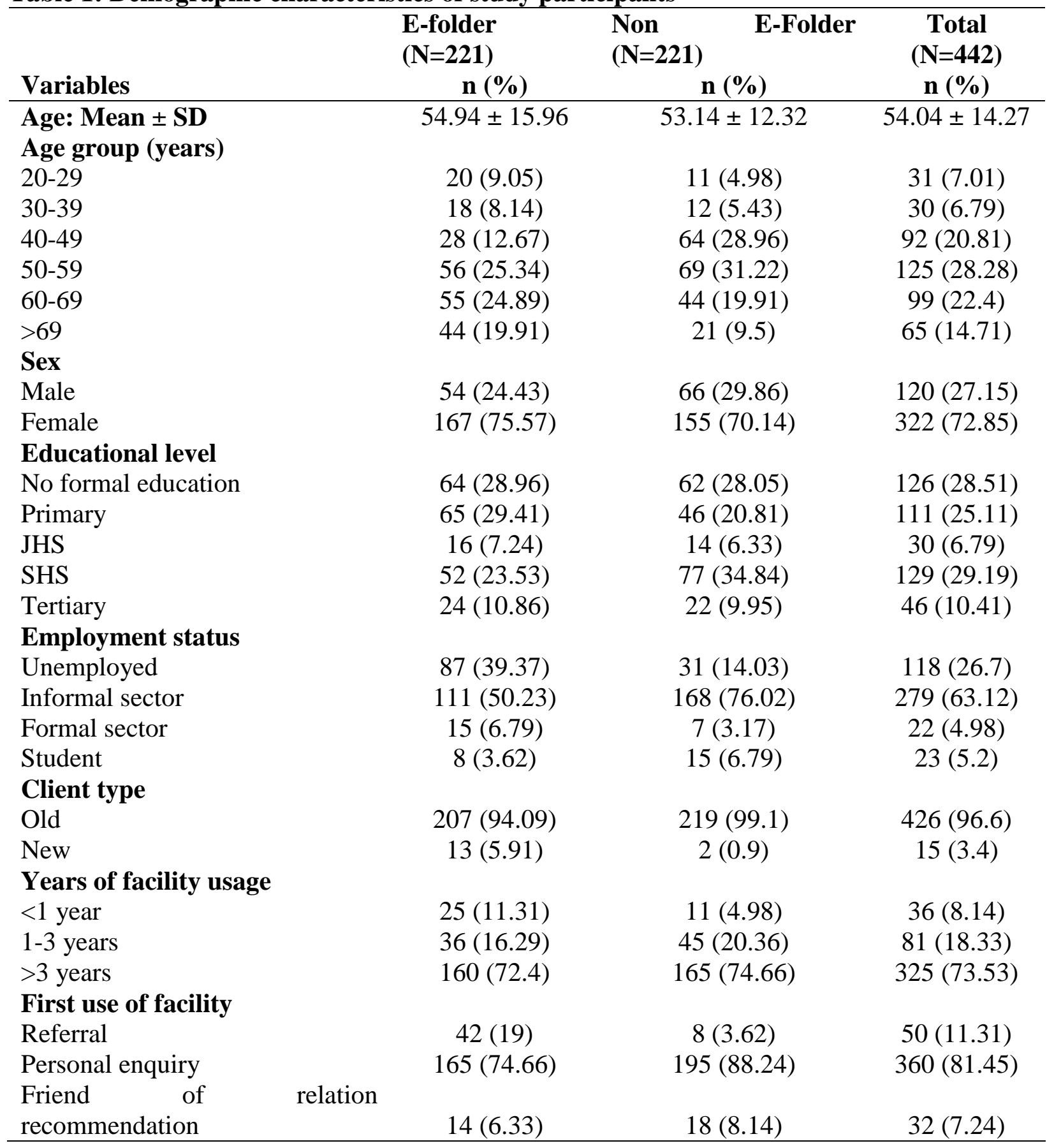

Figure 1 shows the percentage distribution of the prevailing conditions for which the study participant seek treatment from the two health facilities. The most prevailing conditions was cardiovascular diseases such as hypertension and anemia. $50.7 \%$ and $52.0 \%$ of study participants from E-folder and non-E-folder facility respectively were suffering from cardiovascular related conditions. The least suffered condition was musculoskeletal diseases such as leg injury and 
lumbago. In the E-Folder facility $5.0 \%$ of respondents were not informed of their condition and the non-E-Folder facility recorded $5.9 \%$.

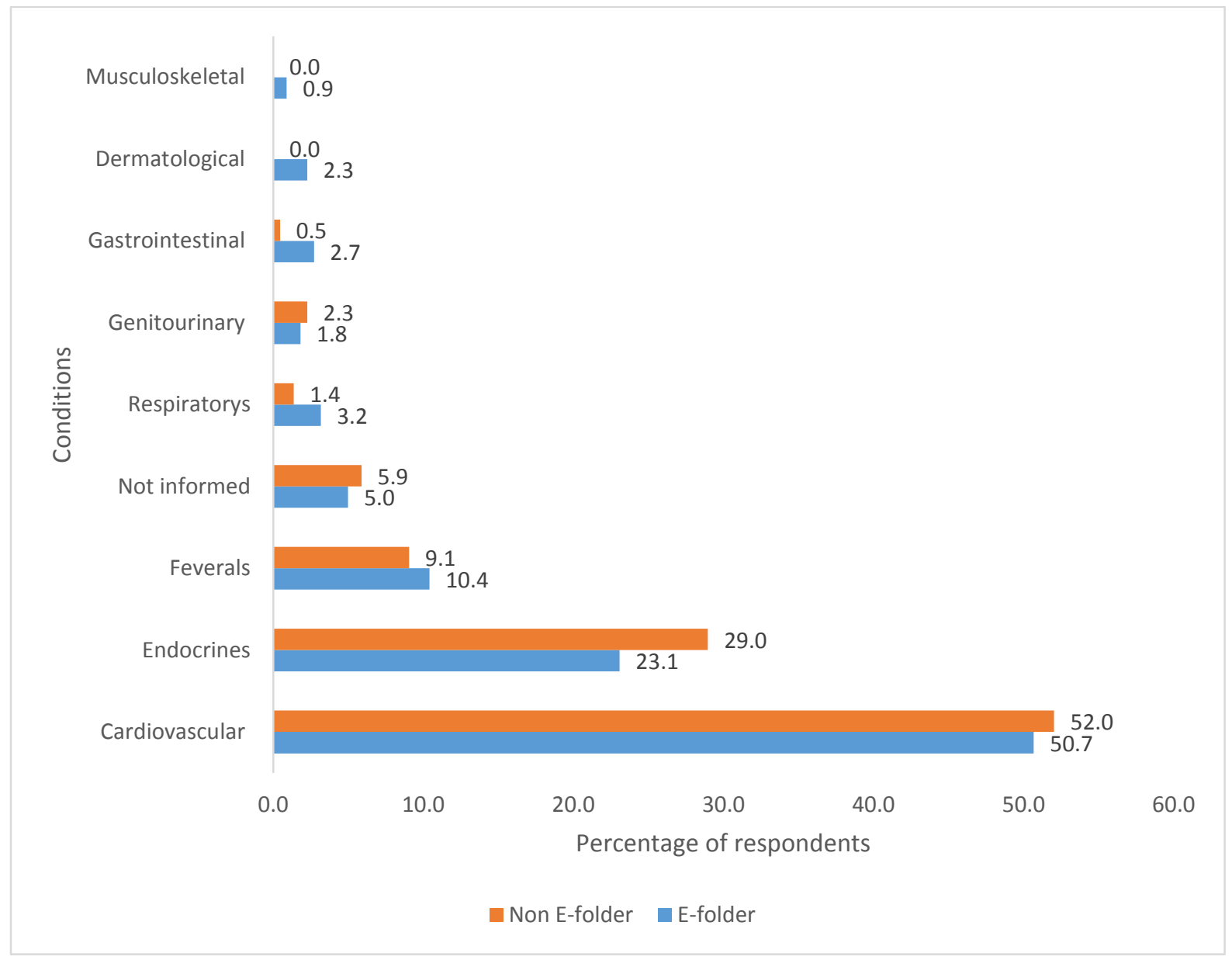

Figure 1: Conditions prevailing among study participants by facility type

\subsection{Patient flow and waiting Time at Outpatient Clinic}

Notably, the mean age of participants from the E-Folder facility estimated as 54.9 years is below the estimated in the results of Farber et al (2017) which was found to be 60.5 years in similar facility; also dominated by Males (96.8\%). In contrast, this study presented $72.9 \%$ of participants as females. This may be due to difference in methods used or be in line with study by Belayneh et al. (2017) that men were found to prefer facilities that offer services within reasonable time because they often want to go back to work in a short time. Current finding indicate that this may not be the case in Ghana. The study revealed that $81 \%$ of OPD diagnosed conditions are noncommunicable and affect adult females most than men and so dominate outpatient clinic attendants; as also indicated in a study by Peck and Kaby (2014) in Tanzania. The Non-E-folder facility presented similar outcome with 53.1 years and a higher percentage of Females $(75.6 \%)$.

Timely care constituted $65 \%$ and $71 \%$ of responses for the outpatients' expectations in both EFolder and Non E-folder facilities. This is consistent with reports of Greenfield et al. (2014) and 
Mehra et al., (2016) who indicated that unlike the inpatient whose satisfaction was based on reflection on curative services overtime, the outpatient who will receive drugs and leave is more concerned about how early he/she will go through all the sections at the outpatient clinic. This increased response can also be likened to Marmor et al.'s (2018) findings. These researchers reported that patients opt for timely care because they perceive maneuvering the outpatient clinic as tiring and so expect to receive care as quickly as possible.

The study showed that total waiting times for both facilities exceeded the standard recommended by the World Health Organisation and the Institute of Medicine, 90-120 minutes. Total waiting time of 236.15 minutes (S.D \pm 81.28 ) and 365.83 (S.D \pm 122.25 ) were discovered in the E-Folder and non-E-folder facilities respectively. This is supported by various studies (Duku et al., 2018; Belayneh et al., 2017; Musingizi, 2013; Weeks, 2013 Kwarteng, 2012;) who found that patients spend an average of 300-360 minutes to assess full care at the OPD. These findings however are typical in a non-E-folder setting. Contrasting findings were recorded in E-Folder facility by Pandit, Varma and Amruta (2016); who found a mean time of 60 minutes. This reduction of average time with the automation of patient record is justified as a reiteration of report by Anjali et al., (2015) who measured a significant decrease from 275 minutes to 196 minutes. Ahmed et al., (2017) recorded 54.07 minutes registration time in non-E-Folder facility whiles Alkan, Kemal, and Erkan (2018) measured 10 minutes in E-Folder facility. This outcome (45.21 \pm 39.87 (Non-E-Folder) and $3.68 \pm 4.34$ (E-Folder) adds to evidence that E-Folder use significantly improves waiting time at registration point with a significance level of $\mathrm{p}<0.001$.

From these total times respondents spent 180.59 minutes (S.D \pm 74.95$)$ and 217.32 minutes (S.D \pm 103.57 ) respectively waiting for full care at various sections. Musingizi, 2013 concluded that out of 346 minutes total waiting time, patients spent $95 \%$ of this period waiting for service. This brings to mind the fact that it is important for hospital administrators and care providers to pay attention to the quality of this wait time for service. Most facilities provide television, as in study sties for this purpose. Nevertheless, over $60 \%$ of respondents from both facilities preferred to be engaged by the health providers; by way of giving a health talk or information on processes to follow or delays. According to supportive literature by Lainer et al., 2017, majority of patients (78\%) perceive this session with the health worker as ensuring quality of wait time and impact satisfaction positively. Belayneh (2015) however, found in his study on patient satisfaction with waiting time that more than $50 \%$ of respondents preferred to watch television whiles waiting.

Contact with provider in the consulting room is seen as vital, in patient care. This study reported an average contact time of 4.1 minutes (S.D \pm 2.59 ) and 5.04 minutes (S.D 3.78) for consulting time respectively. Datuk et al. (2011) reported 15 minutes in their study (thrice the finding of this study) for district hospitals The institute of medicine write that a standard consulting time is not fixed but depends on patients' condition, whether a patient is old or new and the duration of time needed for examination and communication of information; between the provider and patient. Mukhtar, (2013) reported a close figure of 4.3 minutes and the patients' expression of satisfaction with time spent with provider is a relative judgement of appropriateness.

The pharmacy recorded highest mean wait times of 39.22 ( $S . D \pm 27.97)$ for E-Folder facility and 47.26 (S.D 23.07) for non-E-Folder facility. Musingizi, (2013) recorded a higher mean time of 123 minutes for a non-E-Folder facility, compared to Datuk et al., (2011) who reported 6 minutes in an E-Folder facility. These differences may be attributed to factors enlisted by these researchers 
such as workload, availability of staff and logistics cited by Musingizi (2013) and a well-equipped study setting and method of enquiry respectively. This translates to two-thirds $(67.9 \%)$ of respondents spending less than 60 minutes for total service time in the E-Folder facility whiles the majority (32.6\%) of those from non-E-Folder facility spent 60-119 minutes being served.

\subsection{Factors influencing waiting time}

Another objective of this study was to report on factors that contribute to prolong and short waiting times in both facilities. Top factors are discussed below:

The number of people in a queue to be seen by a health provider deciphers their workload. This study found that $26.7 \%$ of respondents in the E-Folder facility had a total of at most 20 people in all queues they joined and $3.6 \%$ had more than 39 people in queues joined. This was an inverse situation for the non-E-Folder facility respondents who recorded $27.6 \%$ and $7.2 \%$. In accordance with Musingizi (2013), who found majority (62\%) of patients coming in before $8 \mathrm{am}, 54.7 \%$ and $72 \%$ of respondents reported before $8 \mathrm{am}$ in E-Folder and Non-E-Folder facilities consistently. Pandit (2018) also write that these patients do so with expectation of receiving care early and exiting. However, Alkan, Kemal and Erkan (2015) also reported that this led to long queues at the outpatient clinic before 10am. Especially, at consulting area, as confirmed by this study with a mean of 12 people ahead of patient. Finding in E-Folder Facility had only 5 people in consultation queue before this time. Both facility respondents also had an estimate of 7 people ahead of them in the pharmacy in the late morning, increasing pharmacy wait times in this study. Sun et al., (2017) also reported in their study that the hold up in the pharmacy queue can also be attributed to all patients from other outpatient clinics and inpatient units converging for drugs, as was the case for both facilities.

Queues not followed accordingly by patients was high on the list of non-E-Folder facility respondents $(84.6 \%)$ and $2^{\text {nd }}$ place for non-E-folder respondents $(25.8 \%)$. Sandiya and Varadharajan (2018) discovered this factor and reported that it arises from poor categorization of patients and first-in first-out server system which is used by both facilities interrupted. Oche and Adamu (2013) also support this finding explaining that interruptions arise from high priority patients like children and the critically ill cutting in. This means that having patients in line in computerized system does not guarantee a first-come first-serve service. Staff preoccupied with other activities constituted $50.7 \%$ and $13.6 \%$ for Non-E-folder and E-Folder facilities. Pandit (2018) also revealed in a root cause analysis that staff may be available at post but may be engaged in administrative work, meeting or involved in emergency care. Network Failure $(19.0 \%)$ was also cited by respondents as an offset in the E-Folder system. Bouayad, Lalynytchev and Padmanabhan, (2017) reported this as a major setback in an electronic health record system. Insufficient staff (36.7\%) and Late reporting of staff (27.2\%) also concur with findings of Hisahiro et al., (2016), who identified these under human resource factors.

Major factors influencing short waiting time were opposites of factors influencing prolong time. The main factors listed as 'Few patients in queue' (70.1\%) and $88.7 \%$ for both facilities; E-Folder facility $69.2 \%$ for 'Network stability' and 'queue followed accordingly' formed $84.6 \%$ for non EFolder facility. This is consistent with study reports by Week (2013) and Mohd and Charkravarty (2014). They both report that with effective administrative systems, a reversal of prolong time factors will transform into short time factors. 


\subsection{Perceptions on patient-provider relationship}

Patient provider relationship is also a vital indicator of outpatient satisfaction. Recent concerns in the healthcare industry surrounding this relative phenomenon have been around the computer in between the patient and provider in the consulting room. This study also researched on the computer as a 'third person' in this relationship to ascertain its impact on patient satisfaction. Perceptions of respondents yielded significant results with $p$-values less than 0.05 . For provider courtesy, a higher percentage $(96.4 \%)$ of respondents from the E-folder facility agreed whereas $85.1 \%$ among those in Non- E-folder facility $\left(\chi^{2}=16.8\right.$, p-value $\left.<0.001\right)$ did same. Mukhtar et al., (2013) found a close figure of $93 \%$ for non-electronic facility respondents. Sun et al., (2017) reported $76.7 \%$ for respondents in an electronic folder system and add that the patient felt respected if a provider regarded him/her. Chandra, Mohammadnezhad and Ward (2018) testified that it formed a basis for trust and compliance to treatment especially for the older patient. These researchers also found that 'provider showing empathy', measured as 'sensitivity to patient's feelings' in this study (90\% for E-Folder and $100 \%$ for Non-E-Folder facilities) was significant for a satisfying relationship. This is confirmed in this study with P-value $<0.001$.

Other important measurements included 'provider ensuring patient's privacy' and 'seeking his/her consent for examination'. Again, these showed a significance with $\mathrm{p}$-value $<0.001$ for both facilities' respondents. Qidwai et al., (2013) also recorded a significant level (p-value < 0.05). Over $60 \%$ of respondents from both facilities disagreed that their provider's gaze was on either the folder or computer than them during consulting interaction. Farber et al., (2015) recorded significance with $75 \%$ responses whiles assessing provider relationship in an E-folder system. These findings could be credited to increasing provider sensitization and awareness creation for effective E-Folder use in a way that does not interfere with communication with patient. Alkureishi, et al., (2016) in a systematic review found similar results and proposed that, the EFolder be used in the health system as most patients endorsed its use. They reported that there was no significant difference in provider communication in both systems as confirmed by this study. There was no significance with patient being 'given adequate time to talk about their illness' or 'provider listening attentively'. Contrary to this finding, Sun et al., (2017) found them significant in their study.

Information on patients' condition and treatment were also significant in this study (p-Value $<0.001)$. The majority response elicited that these were important to patients in both facilities respondents. This could be due to the fact that majority of respondents reported with chronic non communicable diseases and so providers deemed it necessary to provide adequate information. Mukhtar et al., (2013) in assessing patient-provider relationship found a negative response as the majority (48\%) were of the view that their providers fell short in this area. Respondents from their study had a mean age of 34 years and presented with uncomplicated and acute conditions. The younger population are also enlightened and expect more. Not meeting this expectation influenced their judgements negatively. By ethics, the patient is entitled to be informed.

\subsection{Satisfaction with care}

Based on respondents' experiences with waiting time and patient-provider relationship, they rated their satisfaction with care at the outpatient clinics. Respondents in the E-Folder facility obtained a grade of $76.4 \%$ for overall satisfaction whiles $75.5 \%$ from the non-E-folder facility were 
dissatisfied. Estimates of satisfaction levels with some aspects of care showed that satisfaction with time was significantly associated with facility type. $72.0 \%$ of participants from the E-Folder facility were satisfied with time spent whiles only $21 \%$ was recorded for the non-E-Folder facility $\left(\left(\chi^{2}=111.9, p\right.\right.$-value $\left.<0.001\right)$. Longer waiting times have been found by most studies as directly associated to dissatisfaction of the outpatient and hospital managers are constantly seeking means of making it acceptable to patients. Belayneh (2017) found that patients who spent more than 180 minutes expressed high dissatisfaction with care. This was evident in this study, where the majority $(62.59 \%)$ were dissatisfied as their total waiting time exceeded 239 minutes.

Though improved, compared to the non-E-Folder facility overall time, evidence from the E-Folder facility concurs with Anjali et al., (2015) that not all changes in operation yield observed reduction in specific performance indicators in the healthcare system; particularly waiting time. They further explained after their intervention study to reduce waiting time that, computerization of the patients' records resulted in decrease in time particularly at the registration and pharmacy units by close to $21 \%$; this was significant but still patients overall time exceeded the recommended 120 minutes. With an overall waiting time of 85 minutes, $21 \%$ of participants according to Datuk et al., (2011) still rated their time as unreasonable. In line with this study findings, it is appropriate to agree with these researchers that a multiple approach best fit for each section is needed to ensure a reasonable time for patients.

Employment status was found to be statistically significant with influence on overall satisfaction. A greater percentage $(56.63 \%)$ of participants who were in the informal sector (p-value $<0.001)$ expressed satisfaction with care. Unlike in a similar study by Berehe et al., (2018), where greater dissatisfaction was seen among those in the formal (56\%) sector. Researchers attributed this to the fact that people employed by other people had little time on their hands and were in a hurry to get back to work unlike the informal sector where most were self-employed.

\subsection{Influence of waiting time and E-Folder use on patient satisfaction}

From adjusted binary logistic regression, facility type, section waiting time, rating of waiting time and satisfaction with time spent assessing care had significant influence on patient satisfaction ( $\mathrm{p}$ value $<0.05)$ Evidence from multiple logistic regression showed that for those who visited the EFolder facility, the odds of being satisfied with services was six times (AOR: 5.79, 95\% CI: 2.4813.50) more than for those who visited the non-E-Folder facility. A study by Alkan, Kemal and Erkan, (2015) had related results. The E-Folder system preferred by most of the respondents is also a clear inference that people who were aware or had experience with the E-Folder facility were less satisfied with the non-E-Folder system because they considered them a better alternative. In this study, based on total time spent, the adjusted odds of being satisfied with services at the health facility was about 5 times (AOR: 4.93, 95\% CI: 2.63-9.24) for those who were satisfied with the time they spent at the facility compared to those who were not satisfied with the time they spent at the facility. Contrary to study findings of (Lainer et al., 2017; Mehra et al., (2016); Mohd \& Charkravarty, 2014; Mukhtar et al., 2013), who found patient provider relationship greatly influencing patient satisfaction, this study produced a negative result as patient-provider relationship was shown to be an insignificant influence on patient satisfaction at the outpatient clinic. 
American Journal of Health, Medicine and Nursing Practice

ISSN 2520-4017 (Online)

Vol.5, Issue 3, pp $53-69,2020$

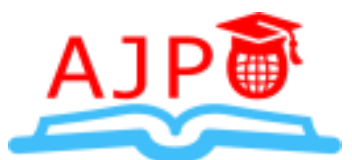

www.ajpojournals.org

\subsection{CONCLUSIONS AND RECOMMENDATION 5.1 Conclusion}

The study found that patients spent an average total waiting time of $236.15 \pm 81.28$ for E-Folder Facility and $365.83 \pm 122.25$ for the Non-E-Folder facility. This exceeded the recommended 90 120 minutes by the Institute of medicine and World Health Organisation.

The major factors contributing to prolong waiting time in the Non-E-Folder facility were 'queue not followed accordingly' (84.6\%), 'Queue' too long' (75.6\%) and 'Staff occupied with other activity' $(50.7 \%)$. Factors in the E-Folder facility included 'Queue too long' (35.8\%), 'Queue not followed accordingly' (25.8\%) and 'Network Failure' (19.0\%). Factors contributing to short waiting times were shown as a reverse of the above factors.

Levels of perception of patient provider relationship was rated as 'good' by majority in both facilities. Respondents in E-Folder facility rated $81.9 \%$ whiles those in the Non-E-folder facility rated $84.2 \%$.

The proportion of respondents satisfied with care under E-Folder and Non-E-Folder systems were $76.47 \%$ and a lower proportion of $24.43 \%$ respectively. Total waiting time was found to be greatly associated with overall satisfaction score (AOR: 4.93, 95\% CI: 2.63-9.24).

The study findings provide evidence of a significant influence of the type of record system on patient satisfaction.

\subsection{Recommendation}

\section{A. Facility level:}

\section{Non-E-Folder facility}

\section{1) To improve waiting time:}

\section{Administration and management:}

1) Patients after visiting the history section should be categorized into groups depending on their age and condition for example, children under 15 years, adult medical patients, surgical patients and seated according to consulting rooms instead of all patients joining a single queue and choosing by themselves which room to go to. This will also reduce the practice of giving priority to 'special' patients which adds to time.

2) Patients folders should be taken and arranged in consulting room according to how they are seated so that misunderstandings will not arise when a patient leaves the queue for any reason and comes back to his/her spot.

3) Patients revisiting the consulting room from laboratory should be arranged in an order instead of patient being left to struggle for re-consultation with their results, adding to their waiting time.

4) To reduce waiting time at the laboratory, there should be designated clinic days for special patients like pregnant women and patients coming for elective surgery screening as for the Diabetic and Hypertensive patients in order to reduce strain on limited staff. Sufficient staff should be added 
to the three permanent staff as floating staff are not reliable. This will also help them to run a functional 24hour service instead of early patients queueing till after 9:00 am to be attended to.

5) At the record section, there should be strict vigilance on filing folders properly and an ordered manner of receiving cards instead of patients putting all their cards into a big box on a chair with high tendency of mix up, much smaller box which can keep cards in order can be put at the counter. Patients should not be made to join separate queues for their National Health Insurance Cards and folders as it a prolongs time. A single queue should serve patient simultaneously so that both services are composite.

6) For all sections late reporting of staff should be checked. Staff should be monitored to report to work early, desist from being involved in activities that delay their service and not related to work such as personal phone calls. Staff changing shift must report before morning shift staff leaves in order to cover the gap of unnecessary wait especially for Doctors.

7) Ultimately, the Electronic folder system can be implemented in the long term as it has been found to significantly contribute to improved waiting times.

\section{Patient engagement and information}

As patients spend over $80 \%$ of total time waiting, engaging them through health talks or intermittent information on processes and any delays will improve quality of their wait time.

\section{Enhancing patient-provider relationship}

Since providers were rated high with interaction, the smaller percentage who were dissatisfied mainly because they did not receive information on their condition and treatment should be targeted for improvement.

\section{E-Folder facility}

\section{To improve waiting time}

\section{Administration and management}

1) Since patients spend less time at registration, the backlog of patients at the history session is inevitable. Additional history tables could be provided to cater for patients, reducing time they spend at this section.

2) On special clinic days, arrangement for doctors to report earlier than the normal 8:30 am to attend to early attendants. If doctors have to be on rounds, at least one should be available at the OPD to start consultation to reduce delay.

3) Frequent network instability should be worked on by technicians as it causes undue delay. Scheduled maintenance for network equipment must be done to reduce rate of breakdown.

4) Staff should have strict discipline to prevent crossing line with their personal and preference patients. 
American Journal of Health, Medicine and Nursing Practice

ISSN 2520-4017 (Online)

Vol.5, Issue 3, pp $53-69,2020$

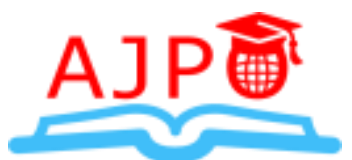

www.ajpojournals.org

\section{Patient engagement and information}

To reduce their anxiety and improve quality of wait time, information on processes and delays as well health talk sessions is recommended.

\section{Enhancing patient-provider relationship}

Providers should improve upon their current mode of interaction and target the few they might have missed.

To improve satisfaction in both facilities, it is necessary to adhere to the biannual patient satisfaction survey mandated by the Ministry of Health, Ghana; in order to ascertain satisfaction scores and identify areas of improvement. It should not be a redundant requirement but seen as a tool for ensuring efficiency. Even though improvement methods can be adopted from other facilities tested, managers should modify them to suit their setting.

\section{B. Policy Makers}

The Electronic Folder system introduced as part of Ghana's Quality Assurance strategy is a laudable venture. Government should however task district leaders and also provide support in terms of finance or provision of computers to facilities that are constrained to implement and maintain its smooth function.

\section{Future research}

Simulation studies should be carried out at facility levels to assist facilities identify measures that improve waiting time peculiar to their setup.

\section{References}

Achampong, E. K. (2012). Electronic health record system: a survey in Ghanaian hospitals. Open Access Scientific Reports. 1(2). 1-4. http://dx.doi.org/10.4172/scientificreports. 164

Adan, I., \& Resing (2015). Queuing Systems. The Netherlands. Retrieved from https://www.win.tue.nl/ iadan/queueing.pdf

Ahmad, B. A., Khairatul, K., \& Farnaza, A. (2017). An assessment of patient waiting and consultation time in a primary healthcare clinic. Malaysian Family Physician: The Official Journal of the Academy of Family Physicians of Malaysia. https://doi.org/10.14260/jemds/2018/225

Ahmad, B. A., Khairatul, K., \& Farnaza, A. (2017). An assessment of patient waiting and consultation time in a primary healthcare clinic. Malaysian Family Physician: The Official Journal of the Academy of Family Physicians of Malaysia. https://doi.org/10.14260/jemds/2018/225

Alkureishi, M.A., lee, W.W., Lyons, M., Press, V.G., Imam, S., Nkansah-Amankra, A., Werner, D. \& Arora, V.M. (2016). Impact of electronic medical use on the patient-doctor relationship and communication: a systematic review. Journal of General Internal Medicine. 31(5). 548-60. doi: 10.1007/s11606-015-3582-1. 
American Journal of Health, Medicine and Nursing Practice

ISSN 2520-4017 (Online)

Vol.5, Issue 3, pp $53-69,2020$

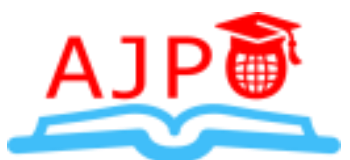

www.ajpojournals.org

Anjali, S., Long, K., Salie, H., Top, S., Sanghvi., S., Niekerk, L., \& A de Sa, (2015). A collaborative action research to reduce persistently long patient wait times in two public clinics in Western Cape, South Africa. The lancet Global Health. 3(S1): S18 doi: $\underline{10.1016 / S 2214-109 X(15) 70137-3}$

Atinga, R. A., Abekah-Nkrumah, G., \& Domfeh, K. A. (2011). Managing healthcare quality in Ghana: A necessity of patient satisfaction. International Journal of Health Care Quality Assurance, 24(7), 548-563. https://doi.org/10.1108/09526861111160580

Batbaatar, E., Dorjdagva, J., Luvsannyam, A., Savino MM., \& Amenta P.(2016). Determinants of patient satisfaction; a systemic review. Perspectives in public health. 137(2). 89-101. https://dx.doi.org/10.1177/1757913916634136

Bouayad, L., Ialynytchev, A., \& Padmanabhan, B. (2017). Patient Health Record Systems Scope and Functionalities: Literature Review and Future Directions. Journal of Medical Internet Research. https://doi.org/10.2196/jmir.8073

Duku, S. K. O., Nketiah-Amponsah, E., Janssens, W., \& Pradhan, M. (2018). Perceptions of healthcare quality in Ghana: Does health insurance status matter? PLoS ONE. https://doi.org/10.1371/journal.pone.0190911

Ehrenfield, J.M., \& Wanderer, (2018). Technology as friend or foe? Do electronic health records increase burnout? Current Opinion in Anaesthesiology 31(3):357-360. http//dx.doi.org/10.1097/ACO.0000000000000588

Evans, R. S. (2016). Electronic health records: then, now, and in the future. Year Book of Medical Informatics. 25(1). 548-561.

Retrieved from https://www.thieme-connect.de/products/ejournals

Garba, K. D., \& Yahya, H. (2018). Significance and challenges of medical records: A systematic literature Review. Journal of Advances in Librarianship. 9(1). 26-31.Retrieved from https://www.researchgate.net/publication/330039863_SIGNIFICANCE_

Greenfield, G., Ignatowicz, A. M., Belsi, A., Pappas, Y., Car, J., Majeed, A., \& Harris,M.(2014). Wake up, wake up! It's me! It's my life! Patient narratives on person-centeredness in the integrated care context: a qualitative study. BMC health Services Research. 14. 619. https://doi.org/10.1186/s12913-014-0619-9

Job, O., Bachmann, L., Schmid, M. K., \& Thiel, M. A. (2013). Assessing the efficacy of the electronic patient record system EDeR: Implementation study - study protocol BMJ Open Access.3. Retrieved from https://i1.rgstatic.net/publication/236195206_Assessing

Koka, T. A., Badshah, \& Shah, R. A. (2017). Single and multi- server queueing models: A study. International Journal of Mathematics and Its Application. 5(4). 595-603.

Marmor, R. A., Clay, B., Marlene, M., Savides, T.J., \& Longhurst, C. A. (2018). The impact of physician EHR usage on patient satisfaction. Applied Clinical Informatics.9(1) 11-14. https://dx.doi.org/10.1055/s-0037-1620263 
American Journal of Health, Medicine and Nursing Practice

ISSN 2520-4017 (Online)

Vol.5, Issue 3, pp $53-69,2020$

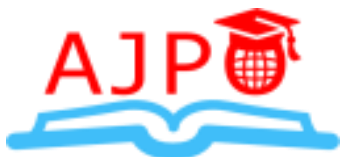

www.ajpojournals.org

Mohd, A., \& Charkravarty, A. (2014). Patient satisfaction with services of the outpatient department. Medical Journal Armed Forces India. 70(3), 237-242. https://dx.doi.org/10.1016/j.mjafi.2013.06.010

Oche, M., \& Adamu, H. (2013). Determinants of patient waiting time in the general outpatient department of a tertiary health institution in north western Nigeria. Annals of Medical and Health Sciences Research. 3(4). 588-592.

Retrieved from https://www.researchgate.net/publication/259500249_Determinants

Ofosu-Kwarteng, J. (2012). Healthcare Delivery and Customer satisfaction in Ghana: a case study of the Koforidua regional hospital (Thesis). Retrieved from http://ir.knust.edu.gh/xmlui/handle/123456789/482

Olomi, G. A., Mboya I.B., \& Manong, I. B. (2016). Patients' level of satisfaction with the healthcare services received at the outpatient departments in Kilimanjaro region, Tanzania. Journal Of Patient Care. 3 (124). http://dx.doi.org/10.4172/2573-4598.1000124

Pandit, A., Varma, E. L. (2016). Impact of OPD waiting time on patient satisfaction. International Education and Research Journal. 2(8). Retrieved from https://www.academia.edu/36959440/

Patel, R., \& Patel, H. R. (2017). A study on waiting time and out-patient satisfaction at Gujarat medical education research society hospital, Valsad, Gujarat, India. International Journal Of Community Medicine And Public Health, 4(3), 857-863. https://doi.org/10.18203/23946040.ijcmph20170772

Pearce, C., Arnold, M., Phillips, C., Trumble, S., 2011, 'The patient and the computer in the primary care consultation', Journal of the American Medical Informatics Association. 18(2), 138-142. https://doi.org/10.1136/jamia.2010.006486

Qidwai, W., Tabbssum R., Khan, F.H., Javed, S., Ali, S. M. \& Nanji, K. (2013). Informed consent, privacy and confidentiality practiced by doctors of a tertiary care hospital in a developing country. Indian Journal of Medical Ethics. 10(1). 36-40

DOI:10.20529/IJME.2013.008

Retrieved from http://ijmaa.in/

Shoenfelder, T., Klewer, J., \& Kluger, J. (2011). Determinants of patient satisfaction: a study among 39 hospitals in an in-patient setting in Germany. International Journal for Quality in Health Care. 23(5). 503-509.

Retrieved from https://academic.oup.com/intqhc/article/23/5/503/1864644

Sreenivas, T., \& Babu, S. N. (2012). A study on patient satisfaction in hospitals (a study on three urban hospitals in Guntur District, Andhra Pradesh). International Journal of Management Research and Business Strategy. 1(1), 101-118. Retrieved from www.ijmrbs.org/view.php?iid=16

Sun, J., Lin, Q., Zhao, P., Zhang, Q., Xu, K., Chen, H., Liu, Y. (2017). Reducing waiting time and raising outpatient satisfaction in a Chinese public tertiary general hospital - an interrupted time series study. BMC Public Health. 17. 668. https://doi.org/10.1186/s12889$\underline{017-4667-\mathrm{Z}}$ 
Weeks, R. V. (2013). Electronic health records: managing the transformation from a paper-based to an electronic system. Journal of Contemporary Management.10. 135-155. Retrieved from https://repository.up.ac.za/bitstream/handle/2263/31892/Weeks

Xie, Z., \& Or, C. (2017). Association between waiting times, service time, and patient satisfaction in an endocrinology outpatient department: a time study and questionnaire survey: a time study and questionnaire survey. Inquiry: The Journal of health Care Organisation, Provision and Financing. 54. https://doi.org/10.1177\%2F0046958017739527 